\title{
Interação e práticas sociais ${ }^{1}$
}

Beatriz Schmidt

Doutora em Comunicação e Cultura pela Escola de Comunicação/UFRJ

e professora da Universidade Estácio de Sá, na graduação e pós-graduação, nas disciplinas:

Teorias da Comunicação e Comunicação Comparada.

E-mail: biaritz@unisys.com.br

\section{A produção e a co-produção de sentidos em práticas sociais comunicativas e educativas}

A proposta de análise deste artigo encontra-se na construção, passo a passo, do processo interacional de um ritual comunicativo-educativo ${ }^{2}$. A idéia de processo interacional está fundamentada em dois eixos centrais: a) as análises apresentadas pela Escola de Palo Alto com a perspectiva das interações sociais, ou seja, a comunicação vista como uma situação global de interação. Conforme Bateson, "a essência da comunicação reside em processos relacionais e interacionais; todo comportamento humano possui valor comunicacional e, por último, a comunicação é um todo integrado, um processo plural permanente";; b) resgatando a idéia de co-autoria, no sentido de correspondência, de reciprocidade, de atividade dialógica, na visão bakhtiniana ${ }^{4}$.

Fundamentalmente, reconhecendo o campo da co-produção (em substituição ao termo recepção) como um espaço de criação, de legitimidade, de autoria e autoridade, admite-se a evidência de uma interação entre produção e co-produção. Portanto, nas práticas sociais em que isto ocorre, mais adequado aos seus objetivos estará o instrumento utilizado, seja ele qual for (qualquer atividade que implica a participação efetiva de todos os envolvidos no processo, como, por exemplo, a elaboração de um vídeo, de uma revista, de um jornal comunitário e outros).

Em diversas experiências já analisadas (além da já citada TV Escola, a avaliação do Programa Canal Saúde da Fiocruz, de 1997, e do Canal Futura, o Canal do Conhecimento, de 1999, entre outras), pode-se evidenciar, efetivamente, um maior poder de intervenção social dos agentes sociais, em suas respectivas comunidades, ao exercerem funções sociais.

\section{NOVAS PRÁTICAS COMUNICATIVAS}

Desde o final da década de 1980, há a ocorrência de uma série de ingerências no campo social, tais como: a emergência das novas tecnologias comu-

1. Artigo baseado na tese de doutorado defendida em março de 2001 na Escola de Comunicação da UFRJ, intitulada "Um ritual de interação" (análise de um processo comunicativo-educativo - o caso TV Escola).

2. A pesquisa que desencadeou esta reflexão foi realizada entre 1997 e 1998 por uma equipe interdisciplinar do Centro de Avaliação da Fundação Cesgranrio (da qual participei), conforme solicitação da Secretaria Especial de Educação a Distância (SEED) do MEC, com o objetivo de avaliar, em todo o território nacional, o Programa TV Escola. Para maiores informações, ver o Relatório Final de Avaliação Nacional do Projeto TV Escola, Fundação Cesgranrio, Convênio MEC/Unesco, Rio de Janeiro, janeiro de 1998. No trabalho que segue, algumas diretrizes serão apresentadas, tendo em vista a possibilidade de aplicação da análise em outras experiências, que tenham o recorte na interface comunicação/ educação.

3. YVES, W. (Org.). La nueva comunicación (Uma nova comunicação). Barcelona: Editorial Kairós, 1964.

4. Importante leitura do capítulo "A arquitetônica da responsabilidade". In: CLARK, Katerina; HOLQUIST, Michael. Mikhail Bakhtin. São Paulo: Perspectiva, 1998. p. 89-116. 
nicacionais; o aparecimento de novos movimentos sociais; de novos contratos sociais; da construção de um novo exercício de cidadania. Surgem também novas formas de adequar as tecnologias comunicacionais a certas práticas sociais, que não passam pelas grandes redes de transmissão de mensagens.

São situações que se operacionalizam a partir dos media, com objetivos específicos, na perspectiva de veicular informações direcionadas a um determinado público-alvo e com características singulares. É o caso de alguns instrumentos aplicados em experiências desenvolvidas por áreas que se caracterizam pela interface com a comunicação, como, por exemplo, a educação, a saúde e outras. Pode-se vislumbrar isto em atividades exercidas, principalmente, por organizações não-governamentais - ONGs e até governamentais, como cooperativas, pastorais e os mais diversos movimentos sociais.

A caracterização do pressuposto acima mencionado advém das perspectivas adotadas por Ricardo Haye em suas análises para pensar o rádio. Em primeiro lugar, busca entender essas novas práticas sociais como um "meio de difusão, isto é, um canal de transmissão de mensagens que buscam objetivos definidos, como um meio capaz de transmitir conteúdos para mudar atitudes" ${ }^{\text {. A segunda }}$ perspectiva é entendê-las como "práticas significantes", isto é, não podem ser "pensadas como canais através dos quais (só) se transmitem conteúdos, mas como espaços nos quais diferentes atores desempenham diferentes papéis, produzindo o sentido em conjunto, (em que) produtores e receptores (co-produtores) adquiram um papel produtivo"6. O usuário dessas práticas não é objeto de um processo, mas parte integrante da prática comunicativa/educativa, com funções determinantes na produção de sentido.

Portanto, pode-se vislumbrar a perspectiva de interação entre produção e co-produção de mensagens do ponto de vista de uma metodologia que será aqui esboçada, de duas formas. Em primeiro lugar, por um certo corpo de conceitos, de proposições que se juntam não de uma forma intencional, mas pelo efeito da transdisciplinaridade, isto é, a partir de uma articulação transdisciplinar; e, em segundo, pela emergência de algumas categorias de interação.

No mundo contemporâneo, já não se pode desvincular, ou mesmo tratar, algumas áreas da produção do saber separadamente. Em recente visita ao Brasil, o pensador alemão Hans Ulrich Grumbrecht constatou, com total propriedade, a importância de pensarmos de forma articulada e transdisciplinar, propondo que "os intelectuais se abram a diversos campos do saber [...] para tentar construir novas áreas de estudo. O papel do intelectual não é encontrar soluções definitivas aos impasses da sociedade, mas produzir complexidades. Temos de

5. HAYE, Ricardo M. Hacia uma nueva radio (Rumo a um novo rádio). Buenos Aires: Paidós, 1995. p. 28-29.

6. Ibid., p. 29

7. BERTIOL, Rachel. O desafio de conectar o intelectual com o dia-a-dia. O Globo, Rio de Janeiro, 14 set. 2000. Segundo Caderno, p. 3. voltar nossa concentração ao que conhecemos bem, mas amplificar, criar talvez um novo campo de especialização"?.

Fica evidente que uma articulação transdisciplinar elaborada a partir do mapeamento de alguns conceitos permitirá o entendimento de um ritual de interação.

Ou seja, por estarmos lidando com campos diferentes - produção e coprodução -, a perspectiva interacional deve ser vista como um processo de relação, de articulação, de negociação, em que os sujeitos atuam com suas experiências e poderes intrínsecos de forma fundamentalmente criativa. 


\section{UMA PERSPECTIVA METODOLÓGICA}

Para elucidar melhor, cabe aqui a idéia de Geertz: "a etnografia do pensamento, como qualquer outro tipo de etnografia - da fé, do matrimônio, do governo, do câmbio - é uma tentativa não de exaltar a diversidade, mas sim de tratá-la com seriedade, considerando-a um objeto de descrição analítica e

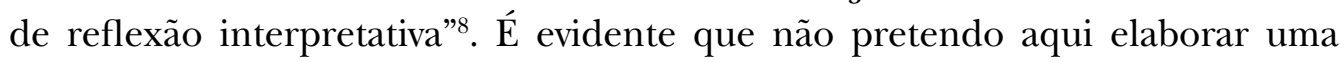
etnografia do pensamento nos moldes de um processo etnográfico propriamente dito, mas a idéia que Geertz ${ }^{9}$ recupera em Kuhn, uma matriz disciplinar, contribuiu para uma tentativa minha de idealizar uma matriz transdisciplinar, a partir da reconstrução metodológica, com o intuito de ajudar na compreensão da perspectiva interacional que estou perseguindo neste texto.

Outra idéia importante que, com certeza, facilita a compreensão dessa perspectiva metodológica é a de Vera Veiga França, quando se refere ao "aspecto da heterogeneidade dos aportes teóricos acionados para a compreensão das práticas comunicativas. Fenômeno empírico com tantas facetas, a comunicação suscita múltiplos olhares, é um objeto complexo que apresenta recortes passíveis de serem investigados por várias disciplinas" ${ }^{10}$.

Portanto, neste caso, recorrendo a vários autores, percebe-se o processo de interação com base na observação das seguintes dimensões ${ }^{11}: 1$ ) a dimensão relacional e de poder; 2) a dimensão mediatizada ou multimediatizada; 3) a dimensão invencional e experimental; 4) a dimensão operacional e circulacional; e 5) a dimensão interacional e negociada.

\subsection{Dimensão relacional e de poder}

Para fazer circular uma mensagem de forma que atinja o maior número de co-produtores, é sumamente importante que a produção tenha total conhecimento do seu público-alvo, quais são os seus interesses, suas histórias de vida, como é o seu cotidiano e principalmente quais são seus parceiros, suas relações dentro e fora da comunidade em que estão inseridos.

Tanto no campo da produção como no campo da co-produção interagem forças que devem ser consideradas sob análise.

Como afirma Bourdieu: “[...] as estratégias discursivas dos diferentes atores, e em especial os efeitos retóricos que têm em vista produzir uma fachada de objetividade, dependerão das relações de forças simbólicas entre os campos [...], ou seja, dependerão dos interesses específicos e dos trunfos diferenciais que [...] lhes são garantidos pela sua posição nos sistemas de relações invisíveis que se estabelecem entre os diferentes campos em que eles participam. [...] o que resulta de todas estas relações objetivas são relações de forças simbólicas que se manifestam na interação. [...] O espaço de interação é o lugar da atualização da interseção entre os diferentes campos"12.
8. GEERTZ, C. O saber local. Petrópolis: Vozes, 2000. p. 231.

9. Ibid., p. 227.

10. FRANÇA, V. V.; MARTINO, L. C.; HOHLFELDT, A. Teorias da comunicação: conceitos, escolas e tendências. Petrópolis: Vozes, 2001. p. 49.

11. A seleção de alguns conceitos (num mapeamento) não foi feita por acaso. Entende-se que os mesmos possuem uma operacionalidade eficaz, a partir da aplicabilidade imediata ao instrumento em questão. Respectivamente recorro aos seguintes teóricos: Bourdieu (dimensão relacional); Foucault (dimensão de poder); Martín-Barbero (dimensão mediatizada); Orozco (dimensão multimediatizada); Goffman (dimensão experimental); Certeau (dimensão invencional); Verón (dimensões: operacional e circulacional) e Bateson (dimensões: negociada e interacional).

12. BOURDIEU, P. O poder simbólico. Lisboa: Difel, 1989. p. 55. 
Entende-se, portanto, que os campos - produção e co-produção - somente criam condições de atualizar seus objetivos, suas estratégias, a partir de uma dimensão relacional de suas respectivas forças simbólicas, o que se dá mediante a existência de um espaço de interação.

Já em Foucault, quando analisa a questão do poder e diz que esse "poder não se dá, não se troca nem se retorna, mas se exerce, só existe em ação, [...] mas acima de tudo em uma relação de força"13 -, identifico a visão da recuperação do receptor como um sujeito ativo, não mais passivo, adquirindo uma postura de co-produtor, quando apresenta o caráter positivo do poder. Foucault traz também a idéia de que o poder está em todo lugar e não em um só; portanto, se há poder em todo lugar, há poder também no campo da recepção - daí co-produção, que até então não tinha esse poder.

Ainda em Foucault, verifica-se: "o que faz com que o poder se mantenha e que seja aceito é simplesmente que ele não pesa como uma força que diz não, mas que de fato ele permeia, produz coisas, induz ao prazer, forma saber, produz discurso" ${ }^{14}$. Afirma-se, portanto, que as práticas sociais que apresentam uma interface entre comunicação/educação, estando em ação, em circulação, mostrando interesses, saberes, poderes e forças convergentes, podem ir modelando as relações entre os campos da produção e da co-produção. Conseqüentemente, possibilitam avaliar o poder intrínseco do campo da co-produção, medida em que o objeto de análise, o instrumento de atuação passam a circular também neste campo, fora do circuito e controle (somente) do campo da produção.

\subsection{Dimensão mediatizada ou multimediatizada}

Não se tem neste ponto espaço suficiente para aprofundar os conceitos de mediação (Martín-Barbero) e multimediação (Orozco); pressupõe-se o entendimento. O que interessa nesta reflexão passa pela perspectiva de que a proposta de interação aqui esboçada, necessariamente, está fundamentada na idéia de um tripé, ou seja, as mediações (ou multimediações) de caráter institucional, pessoal, cultural, tecnológico (e outras), que circulam nos dois campos de atuação de qualquer prática social, ocasionam as articulações, as negociações e as apropriações, que são instâncias geradoras da interação.

3. FOUCAULT, M. Micro-

física do poder. 6. ed. Rio de Janeiro: Graal, 1986. p. 175.

14. Ibid., p. 8.

\subsection{Dimensão invencional e experimental}

A aproximação entre os conceitos de experiência (Goffman), de consumo (Canclini) e de invenção (Certeau) não é feita por acaso, e sim a partir de uma articulação transdisciplinar, na medida em que se admite que os sujeitos, os co-produtores, colocam, no plano da interação com a produção, as suas experiências singulares, suas realidades e seus enquadramentos, como também inventam a sua maneira e não se limitam exclusivamente ao que a produção lhes oferece; têm os seus próprios projetos e as suas constituições comunicativas no uso do recurso em questão. 


\subsection{Dimensão operacional e circulacional}

Verón ${ }^{15}$ mostra que uma teoria da produção social dos discursos não pode reduzir-se à constituição de modelos, das regras de engendramento do discurso; portanto, não se pode limitar a um estudo (somente) da produção. O efeito de sentido, ou melhor, as leituras são o ponto de acesso à análise das operações discursivas, as quais se dão tanto na esfera da produção do discurso como na esfera da co-produção, ambos espaços de circulação dos discursos. Entende-se que os sujeitos operam, investem, constroem e produzem discursos.

A produção é um conceito ativo e toda ação é um lugar de produção de sentido, enfim, um lugar de disputa de sentido, no qual se efetivam as negociações e se visualiza o processo interativo, oferecendo possibilidades de intervenção social por parte dos envolvidos na ação.

Nessa perspectiva, identifica-se a análise, com a reflexão de Verón, à medida que os campos envolvidos no processo interacional devem absorver a estratégia de que o campo da produção é também um campo receptor de um discurso diferente daquele produzido anteriormente e, vice-versa, o campo da co-produção é também um campo produtor de sentido.

\subsection{Dimensão interacional e negociada}

Elucida-se, neste momento, a pertinência dos conceitos de interação e negociação, elaborados por Bateson. Parte-se do pressuposto de que a co-produção produz um outro discurso, apropriando-se do anterior, que foi elaborado pelo campo da produção. Surge, portanto, a necessidade de se efetivar uma negociação entre discursos diferentes para que ocorra um (ritual) processo de interação visível e viável a qualquer prática comunicativa/educativa. A interação é aqui vista como um lugar em que vão se constituindo vínculos entre as ofertas e os consumos comunicativos. A idéia de interação que se persegue, evidentemente, não passa pela perspectiva de simetria ou assimetria; implica um contexto bem mais complexo, de pura dinâmica, de efervescência, de conflitos e tensões e, principalmente, atravessado por contradições e negociações.

\section{CATEGORIAS DE INTERAÇÃO}

Em qualquer análise que se faça do processo interacional de um ritual comunicativo/educativo, torna-se relevante verificar: as mediações inerentes aos campos; a construção de apropriações, resultantes de negociações e articulações efetivadas pelo campo da co-produção, e finalmente a exposição de protocolos, no sentido de contratos preestabelecidos pela esfera da produção e, principalmente, aqueles desenvolvidos pela co-produção.

No contexto da pesquisa de avaliação do Programa TV Escola, as mediações foram definidas da seguinte forma: "conjunto de recursos e intervenções intro-

15. VERÓN, E. A produção de sentido. São Paulo: Cultrix/USP, 1979. 
duzidas na prática dos usuários e/ou provocadas pelos próprios, diferenciadas ou não daquelas propostas iniciais da produção da TV Escola, que facilitam a inserção da mesma no universo escolar"16. Pela ótica da produção, as mediações passam por várias instâncias - no caso da TV Escola, ou seja, desde as parceiras envolvidas no projeto, passando pela própria Secretaria Especial de Educação a Distância (SEED) do MEC, pelas Delegacias do MEC, até as Secretarias Estaduais; enfim, toda a estrutura burocrática até as mediações que passam pela própria produção dos programas, pelas produções estrangeiras de sofisticada qualidade, que são em maior escala, e outras produções nacionais, incluindo as iniciativas do campo da co-produção.

Foram indicados como representativos das categorias de mediações, no contexto do campo da co-produção, os seguintes aspectos: a) características administrativas, formas de gerenciamento e modelos alternativos de gestão apresentados pelas escolas que usam o Programa TV Escola; b) função de capacitação da TV Escola e desenvolvimento de estratégias de capacitação; c) formas de mediação: o professor como mediador e a função do vídeo; e d) relação de mediação com conteúdos e sua devida compatibilização com os fins pedagógicos.

Quanto à categoria de apropriações no universo da pesquisa de avaliação da TV Escola, verificou-se que: "apropriações são as ações desenvolvidas pelos co-produtores a partir do seu encontro com a oferta produtiva, transformandoa em novos produtos que tragam as suas peculiaridades" ${ }^{17}$. Portanto, pode-se determinar com precisão os seguintes aspectos: a) formas de apropriação e suas múltiplas linguagens; b) articulação entre forma e conteúdo; c) ação do co-produtor/co-autor sobre a oferta comunicativa; e d) novos nichos de consumo. A perspectiva de apropriação por parte da co-produção não é de todo desconhecida por aqueles que fazem parte da produção da TV Escola.

E, por último, a perspectiva interacional perseguida até aqui também pode ser verificada a partir do reconhecimento dos protocolos pertencentes a cada esfera participante do processo.

Todo processo interativo de produção e disputa de sentido pressupõe o poder de dizer, de mostrar, de fazer saber, de fazer crer e de interagir.

Os protocolos - poderes que cada campo exerce - são efetivados mediante regras, contratos e, normalmente, são de natureza discursiva. Por meio deles, os sujeitos se defrontam e estruturam suas estratégias discursivas, fundamentais nas ações e reações dos atores ante a oferta comunicativa/educativa.

A devida análise dos processos de mediações, de apropriações e os protocolos constatam a existência de uma maior aproximação, da possibilidade de interação entre a produção e co-produção de práticas sociais cuja interface

16. SEGUNDO RELATÓRIO FINAL DE AVALIAÇÃO NACIONAL DO PROJETO TV ESCOLA. Rio de Janeiro: Fundação Cesgranrio, Convênio MEC/UNESCO, p. 44 , jan. 1998

17. Ibid., p. 44 passa pela comunicação e educação.

\section{PONTOS CONVERGENTES}

Os dois campos - produção e co-produção - constituem a grande cena de um sistema micro e macro de interações. Como explicitei antes, tanto no 
campo da oferta quanto no campo do consumo encontram-se competências tais como: poder, saber, dizer e interagir, resultantes de gramáticas e experiências de cada um deles. Uma tensão discursiva (disputa de sentido) se dá em virtude das heterogeneidades existentes nos dois campos.

O processo interacional só será efetivado mediante negociações, constituídas por rituais específicos de cada campo (produção e co-produção), ou seja, não mais um total domínio da prática comunicativa por parte da produção, nem mais uma submissão do antigo campo da recepção, fundamentalmente, a invenção de um discurso outro, decorrente de uma interação ${ }^{18}$. Em outras palavras, a interação de um ritual comunicativo/educativo é um processo que ultrapassa os campos envolvidos, constitui-se numa engrenagem entre produção, produto e co-produção, que se articulam mediante alguns critérios: a) é um processo que se efetiva a partir de relações entre campos diferentes, o da produção e co-produção; b) esses campos interagem e negociam entre si por regras, contratos discursivos preestabelecidos; c) cada um desses campos contribui nessa interação com suas experiências específicas; d) nesse processo interacional/relacional verifica-se a circulação dos discursos; e) e é nesse espaço que acontecem a produção e a disputa de sentido, a partir de operações discursivas produzidas pelos dois campos; f) o poder, na perspectiva foucaultiana já citada, estrutura os campos, na medida em que perpassa as relações sociais e os constitui na ação; o poder e o saber se articulam, na prática discursiva, para a construção de sentido; g) e, finalmente, reafirma-se que não se verifica uma linearidade ou uma simetria nessa perspectiva de interação; pelo contrário, constitui um espaço atravessado por contradições, tensões e conflitos, enfim, um espaço necessariamente de trocas.

A produção de sentido não se verifica em nenhum dos espaços (campos) envolvidos na ação comunicativa/educativa, mas na interação entre eles, precisamente, no processo interativo que deve ser provocado em qualquer prática social, com o objetivo de intervenção social ${ }^{19}$.

Para concluir, essas práticas sociais, em muitos casos de abrangência nacional e internacional, lidam com heterogeneidades, com propósitos e públicos específicos, com identidades culturais diferentes. $\mathrm{O}$ elo que as unifica encontra-se na perspectiva de contribuir para uma melhor adequação dos sistemas comunicacional e educacional, nas comunidades em que atuam. As funções social, mobilizadora e de intervenção dessas experiências são os elementos que possibilitam uma interação entre seus participantes, sejam eles da esfera da produção ou da co-produção. Dito isto, esclarece-se que a ênfase desta análise gira em torno dos caminhos adotados e já demonstrados como viáveis por algumas experiências que se encontram em pleno funcionamento. Como também outros caminhos a serem superados em prol da viabilização eficaz de outras experiências. $\mathrm{O}$ foco central é mostrar que a busca pela interação é pertinente na medida em que leva ao melhor desempenho dessas novas práticas comunicativas/educativas.
18. Historicamente falando nas teorias que fundamentam as análises sobre a comunicação, verifica-se o seguinte: um cenário de persuasão, manipulação e controle por parte do campo da produção midiática, como os estudos norte-americanos, nos anos 1930 a 1950, de recorte funcionalista. Em seguida, por volta dos anos 1960 a 1980, nota-se uma ênfase na captura da recepção pelos estudos europeus, com uma perspectiva estruturalista. $O$ que queremos dizer é que não se pode evidenciar um ritual de interação, aqui mencionado, através de uma exposição/ apropriação por parte do campo da produção, como também uma exacerbação do campo da recepção. Os estudos mais recentes apontam para a necessidade de análises que contemplam essa interação, que ocorre a partir do reconhecimento da produção de sentido nos dois campos.

19. Importante leitura de Comunicação e Discurso, de Milton José Pinto. São Paulo: Hacker Editores, 1999. p. 23. 
Resumo: Este artigo se propõe a apontar algumas diretrizes para uma metodologia de análise, que possa detectar um processo de interação entre campos diferentes de atuação, ou seja, a produção e a coprodução de sentidos em práticas sociais comunicativas/educativas. A pertinência da operacionalização desse recorte interacional leva-nos a admitir a viabilidade de um efetivo poder de intervenção social dos participantes dessas experiências.

Palavras-chave: comunicação, educação, produção, co-produção, interação, intervenção social.
Abstract: This article aims at pointing out some guidelines for an analysis methodology, which might be able to detect an interaction process between different fields of performance, that is, the production and co-production of meanings in educational/communicative social practices. The relevance of the operationalization of this interactional cut/view leads us to admit the viability of the social intervention power of the participants of these experiences.

Keywords: communication, education, production, co-production, interaction, social intervention power. 